\title{
Proposing a standardized method for evaluating patient report of the intensity of dyspnea during exercise testing in COPD
}

This article was published in the following Dove Press journal:

International Journal of COPD

26 May 2012

Number of times this article has been viewed

\author{
Asha Hareendran' \\ Nancy K Leidy ${ }^{2}$ \\ Brigitta U Monz ${ }^{3}$ \\ Randall Winnette' \\ Karin Becker ${ }^{3}$ \\ Donald A Mahler ${ }^{4}$ \\ 'United BioSource Corporation, \\ London, UK; ${ }^{2}$ United BioSource \\ Corporation, Bethesda, MD, USA; \\ ${ }^{3}$ Boehringer Ingelheim, Ingelheim, \\ Germany; ${ }^{4}$ Dartmouth Medical School, \\ Hanover, NH, USA
}

Background: Measuring dyspnea intensity associated with exercise provides insights into dyspnea-limited exercise capacity, and has been used to evaluate treatment outcomes for chronic obstructive pulmonary disease (COPD). Three patient-reported outcome scales commonly cited for rating dyspnea during exercise are the modified Borg scale (MBS), numerical rating scale for dyspnea (NRS-D), and visual analogue scale for dyspnea (VAS-D). Various versions of each scale were found. Our objective was to evaluate the content validity of scales commonly used in COPD studies, to explore their ability to capture patients' experiences of dyspnea during exercise, and to evaluate a standardized version of the MBS.

Methods: A two-stage procedure was used, with each stage involving one-on-one interviews with COPD patients who had recently completed a clinic-based exercise event on a treadmill or cycle ergometer. An open-ended elicitation interview technique was used to understand patients' experiences of exercise-induced dyspnea, followed by patients completing the three scales. The cognitive interviewing component of the study involved specific questions to evaluate the patients' perspectives of the content and format of the scales. Results from Stage 1 were used to develop a standardized version of the MBS, which was then subjected to further content validity assessment during Stage 2 .

Results: Thirteen patients participated in the two-stage process $(n=6 ; n=7)$. Mean forced expiratory volume in 1 second $\left(\mathrm{FEV}_{1}\right)$ percent predicted was $40 \%$, mean age 57 years, and $54 \%$ were male. Participants used a variety of terms to describe the intensity and variability of exercise-induced dyspnea. Subjects understood the instructions and format of the standardized MBS, and were able to easily select a response to report the level of dyspnea associated with their recent standardized exercise.

Conclusion: This study provides initial evidence in support of using a standardized version of the MBS version for quantifying dyspnea intensity associated with exercise in patients with COPD.

Keywords: Borg scale, dyspnea assessment, COPD, exercise testing

\section{Introduction}

Dyspnea is clinically the most relevant symptom of chronic obstructive pulmonary disease (COPD) that limits physical activity ${ }^{1}$ and leads patients to seek medical intervention. Reduced capacity for physical activity is a typical consequence of airflow obstruction in COPD patients, and can be measured by testing the patient's exercise capacity in the clinic. The evaluation of dyspnea during exercise has been recommended and is used for the assessment of disease severity and progression, to set targets for treatment, and to evaluate the efficacy of interventions for the management
Correspondence: Asha Hareendran Senior Research Scientist, United BioSource Corporation, 26-28 Hammersmith Grove, Floor 5E, London, W6 7HA, UK Email asha.hareendran@ unitedbiosource.com 
of COPD. ${ }^{2,3}$ Although patients' reports of dyspnea during activity around the home can offer insight into the impact of disease and treatment on patients' daily lives, the variation in these assessments can create measurement challenges. ${ }^{4,5}$

The assessment of improvement in exercise capacity using cardiopulmonary exercise testing (CPET), where the physical stimulus is standardized, has been suggested as an efficacy endpoint for clinical trials, to evaluate response to treatments for COPD. ${ }^{6}$ This approach provides the most comprehensive physiological evaluation of exercise-related symptoms in cardiovascular and respiratory diseases, and a formal measurement of dyspnea during CPET is increasingly used as an outcome for evaluating COPD treatment. ${ }^{2,7,8}$ However, inconsistent results have been observed in clinical trials evaluating the effect of bronchodilators on exercise capacity, and variations in the design of such studies have been identified as a potential factor driving these inconsistencies. ${ }^{8}$ One of the variations noted in study designs is the tools used to evaluate dyspnea during CPET in these studies.

Various factors must be considered in selecting tools to collect data in CPET studies used to evaluate treatment benefits. Guidelines from regulatory agencies ${ }^{9}$ have emphasized the need for demonstrable content validity of outcome measures which are intended to provide data in support of treatment benefit claims. ${ }^{10,11}$ The guidelines suggest that, to confirm content validity, there should be "evidence that the instrument measures the concept of interest, including evidence from qualitative studies that the items and domains of an instrument are appropriate and comprehensive relative to its intended measurement concept, population and use." This evidence is collected using qualitative methods; specifically, focus groups or individual interviews with patients..$^{10,11}$ Patients' preferences and cognitive assessments of existing tools are also important for their acceptance in routine clinical and trial settings. While the optimal time to collect this data would be during the development of a new tool, it is also possible to collect data to retrospectively understand and document content validity of an existing tool using these methods. ${ }^{11}$

The objective of the current study was to assess the content validity of the scales commonly used in COPD studies, to explore their ability to capture patients' experiences of dyspnea associated with exercise, and to evaluate a standardized version of the modified Borg Scale (MBS) for collecting data about dyspnea (breathlessness) intensity associated with exercise in patients with COPD.

\section{An overview of patient-reported outcome scales used for evaluating dyspnea during an exercise test}

The American Thoracic Society (ATS)/American College of Chest Physicians (ACCP) statement on CPET recommends two single-item scales - the modified Borg Scale (MBS) and the visual analogue scale for dyspnea (VAS-D) - for quantifying dyspnea during an exercise test. ${ }^{2}$ Simple numerical rating scales (NRS-D) have also been used in COPD studies.

\section{MBS for rating dyspnea}

Various adaptations have been made to the Borg CR10 Scale $^{\circledR 12}$ to measure the intensity of dyspnea in asthma and COPD trials. The versions of the scales that have been adapted to evaluate dyspnea have been referred to as the modifications of the Borg scale/category ratio scales, ${ }^{13-17}$ and cite the 1982 paper "Psychophysical bases of perceived exertion" by Borg ${ }^{18}$ as the source of the scale. Although this suggests that the same instrument has been used across studies, a closer examination of these studies indicates that the content (instructions, scale range, and labels) and format (eg, verbal, computer screen) of the MBS varies considerably.

Borg ${ }^{18}$ describes a 15 -grade categorical rating scale, called the rate of perceived exertion (RPE) scale, that had scores ranging from 6 to $20 .{ }^{19}$ However, the original category ratio scale, now called the Borg CR10 Scale ${ }^{\circledR}$, was presented at a symposium in $1980 .{ }^{12}$ The original scale was referred to as a numerical category scale for use in various situations where estimates of subjects' perception of intensity of any experience are required. The scale was constructed as a $0-10$ categorical scale with ratio-level properties, incorporating nonlinear spacing of verbal descriptors of the level of intensity (see Figure 1). The authors noted that the maximal intensity level was placed outside of a 0-10 scale, to diminish a ceiling effect. The more recent Borg CR Scales $^{\circledR}$ folder ${ }^{20}$ describes the Borg CR10 Scale ${ }^{\circledR}$ with the categories similar to the 1982 scale, but has 19 points that can be selected (see Figure 1). This document also describes another "fine-graded" version of the scale: the Borg CR100 Scale, with a $0-100$ scaling.

In this paper, we refer to the modifications of the Borg CR10 Scale ${ }^{\circledR}$ for evaluating dyspnea as the Modified Borg Scale (MBS). The MBS scaling most often used to measure dyspnea in COPD literature is the $0-10$ scale. ${ }^{2,21}$ Two methods of scaling are described below. 


$\begin{array}{ll} & \text { Borg CR10 Scale (1982) } \\ 0 & \text { Nothing at all } \\ 0.5 & \text { Extremely weak (just noticeable) } \\ 1 & \text { Very weak } \\ 2 & \text { Weak (light) } \\ 3 & \text { Moderate } \\ 4 & \text { Somewhat strong } \\ 5 & \text { Strong (heavy) } \\ 6 & \\ 7 & \text { Very strong } \\ 8 & \\ 9 & \\ 10 & \text { Extremely strong (almost max) } \\ \text { - } & \text { Maximal }\end{array}$

Borg CR10 Scale ${ }^{\circledR}(\mathbf{2 0 1 0})^{20}$
Nothing at all
Extremely weak Just noticeable
Very weak
Weak
Moderate
Strong
Very strong Heavy
Extremely strong
Absolute maximum Highest possible

Figure I The original Borg CRIO Scale ${ }^{\circledR}$ used to measure the perception of intensity of any experience compared to the Borg CRI0 ${ }^{\circledR}$ Scale in the recent Borg CR Scales folder. The Borg CRIO Scale ${ }^{\circledast}$ with instructions can be obtained for a minor fee from Borg Perception, Rädisvägen I24, S-16573, Hässelby, Sweden.

\section{Modifications of the Borg scale to measure dyspnea - maximal intensity at 10}

In a publication in 1982, Burdon and colleagues ${ }^{22}$ described an MBS to study breathlessness as a function of airflow obstruction in patients with asthma (Figure 2). Subjects were asked to score breathlessness by selecting a number or words that most appropriately described their sensation of breathlessness. Subjects were free to select either whole numbers or fractions, and were instructed to score only their sensation of breathlessness and ignore other sensory stimuli, such as nasal or throat irritation. In a later study evaluating the usefulness of the scale in assessing the degree of dyspnea in patients with COPD and asthma, ${ }^{23}$ Kendrick et al used a version that included the term "breathlessness" in some of the response options to provide clarity, and reported a tabular format for the scale (Figure 2). The ATS Statement: Guidelines for the Six-minute Walk Test, published in $2002^{21}$ and suggesting the use of the "Borg scale" to evaluate both dyspnea and fatigue during the walk test, described the scale with the maximal of the scale at 10, "very, very severe (maximal)." This statement cites the paper describing the RPE scale as the source of the scale. The validity and reliability of the MBS (with a maximal rating of 10) have been examined for use as an evaluative instrument for studying dyspnea over a period of time. ${ }^{24-26}$

\section{Modifications of the Borg scale to measure dyspnea - maximal intensity beyond 10}

In 2001, Mahler et $\mathrm{al}^{27}$ used a computerized version of the scale, whereby the person can report ratings of breathlessness spontaneously and continuously during an exercise by moving a computer mouse that adjusts a vertical bar adjacent to a $0-10$ scale positioned on a monitor. The scale descriptions are similar to those described in the Burdon article, but include 13 points - thus permitting selection of a point beyond a maximal rating of 10 to indicate maximal intensity, as in the original CR10 Scale $^{\circledR}$.

In 2003, the ATS/ACCP statement on $\mathrm{CPET}^{2}$ recommended the use of the CR10 Scale ${ }^{\circledR}$ to evaluate dyspnea during CPET. The statement also describes the format, allowing subjects to select a number greater than 10 as maximal, as in the original $\mathrm{CR} 10^{\circledR}$ Scale. The validity and reliability of the MBS that allows for the maximal rating beyond 10 has also been examined for use in the continuous measurement of dyspnea during exercise. ${ }^{27}$

\section{Visual analogue scale (VAS)}

While use of VAS to evaluate dyspnea in exercise testing is mentioned in several articles, ${ }^{28,29}$ the content and format of the tools themselves were not described. When discussing outcome measures for COPD, Cazzolo and colleagues 


\begin{tabular}{ll} 
A & \multicolumn{2}{l}{ Modified Borg scale - Burdon et $\mathbf{a l}^{22}$} \\
0 & Nothing at all \\
0.5 & Very, very slight (just noticeable) \\
1 & Very slight \\
2 & Slight \\
3 & Moderate \\
4 & Somewhat severe \\
5 & Severe \\
6 & \\
7 & Very severe \\
8 & \\
9 & Very, very severe (almost maximal) \\
10 & Maximal
\end{tabular}

Figure 2 Versions of the modified Borg scale used to evaluate dyspnea.

(A) Reprinted from: Am Rev Respir Dis. 126(5), Burdon, et al. The perception of breathlessness in asthma, 825-828; Copyright (1982); With permission from American Thoracic Society. (B) Reprinted from: Journal of Emergency Nursing, 26(3), Kendrick et al, Usefulness of the modified 0-10 Borg scale in assessing the degree of dyspnea in patients with COPD and asthma, 216-222, Copyright (2000); With permission from Elsevier.

described the VAS-D as a vertical or horizontal line, usually 100 millimeters $(\mathrm{mm})$ in length, with descriptors positioned at the extremes of the scale as anchors. ${ }^{30}$ Anchors for the VAS-D have not been standardized. ${ }^{31}$ Two frequently-used anchor sets are "not breathless at all"/“extremely breathless" and "no shortness of breath"/"shortness of breath as bad as can be." 32 A VAS is typically scored by measuring the distance from the bottom of the scale (or left side if oriented horizontally) to the level indicated by the subject.

\section{Numerical rating scale (NRS)}

The NRS is an instrument that is commonly used to assess patients' experiences with symptoms (eg, pain). Gift and Narsavage $^{33}$ found that the NRS for dyspnea (NRS-D) highly correlated with a 0-100 mm VAS-D, and suggested that the NRS may be an easier scale to use to assess shortness of breath in general assessment settings.

\section{Methods}

\section{Study design}

This was a qualitative, content validity study involving interviews with men and women who had a medical diagnosis of COPD and had recently (ie, within $<24$ hours) completed a supervised, standardized exercise on a cycle ergometer or treadmill. The interviews were conducted in two stages, with six patients included in Stage 1, and seven patients included in Stage 2.

During the Stage 1 interviews, following open-ended discussion for concept elicitation, participants were asked to complete the scales by marking two responses for dyspnea on a paper version of the scale: one to indicate the level of dyspnea experienced before exercise, and the second to indicate the most severe dyspnea experienced during exercise. Results from Stage 1 were used to develop a standardized version of

B Modified Borg scale - Kendrick et al ${ }^{23}$
\begin{tabular}{|l|l|}
\hline 0 & No breathlessness at all \\
\hline 0.5 & Very, very slight (just noticeable) \\
\hline 1 & Very slight \\
\hline 2 & Slight breathlessness \\
\hline 3 & Moderate \\
\hline 4 & Somewhat severe \\
\hline 5 & Severe breathlessness \\
\hline 6 & \\
\hline 7 & Very severe breathlessness \\
\hline 8 & \\
\hline 9 & Very, very severe (almost maximal) \\
\hline 10 & Maximal \\
\hline
\end{tabular}

the modified Borg scale (MBS(S)), which was subjected to further content validity assessment during Stage 2 .

For Stage 2, to mirror the potential methods of use of the scales in clinical trials, participants were asked to select three responses from their recollections of their experiences with breathlessness during their most recent exercise: before the exercise, at the most severe level of breathlessness during exercise, and at about one minute following the end of the exercise. The administration of the scales and instructions simulated the experience of responding during exercise (the method that would be used in clinical trials), with the interviewer holding the scale and instructing the participants to point to responses for each scale, rather than writing the response on paper. Interviewers administered the measures in random order to the participants.

Three measures were tested in this study: the VAS-D, the NRS-D, and the MBS. The VAS-D tested in this study was a vertical 100-mm scale, with 0 ("no breathlessness") at the bottom, and 100 (representing "extremely severe breathlessness") at the top. As the VAS-D is not commonly used in clinical practice or studies, and considering the results of the patient interviews in Stage 1 (see below), the VAS-D was not tested further in Stage 2.

The second measure tested in this study was the NRS-D. NRS-D instructions ask subjects to indicate how much shortness of breath they are having right now, and the 11-point horizontal response scale ranges from 0 ("no shortness of breath") to 10 ("shortness of breath as bad as can be"). Subjects were asked to select the number that they believed represented their current level of breathlessness.

The third measure tested in this study was the MBS. For Stage 1, the version of the MBS used by Kendrick and colleagues $^{23}$ was tested. Based on the results of the patient interviews from Stage 1, as well as team discussions about 
versions used more often in clinical trials and rehabilitation settings, a decision was made to use a version of the scale, and develop standardized instructions to provide additional clarity to participants.

The standardized version, $\operatorname{MBS}(\mathrm{S})$, was based on the version used by Burdon and colleagues, ${ }^{22}$ which was the version used most often in the clinical and trial settings. The instructions were adapted based on the wording used in previous clinical trials; ${ }^{34}$ borders were added to the scale's layout to frame the response options. Figure 3 shows the version of the tool with patient instructions tested in Stage 2.

\section{Participant recruitment}

Participants were recruited from three pulmonology offices associated with one pulmonary rehabilitation clinic near Pittsburgh, PA (in the US). After obtaining Institutional
Review Board (IRB) approval, potential participants were screened for study eligibility by site staff using a screening script to ensure that participants met all prespecified inclusion/exclusion criteria.

The sample included patients with a current medical diagnosis of moderate (Global Initiative for COPD [GOLD] Stage II), severe (GOLD Stage III), or very severe (GOLD Stage IV) COPD (including chronic bronchitis and/or emphysema), documented via lung function testing within the previous year. Participants had to be aged 40 years or older, with a smoking history of at least 10 pack/years. Additionally, participants were required to be currently enrolled in a pulmonary rehabilitation program with lower-limb exercise; motivated to exercise to a point of breathlessness, as required during the most recent experience; able to participate in a oneon-one interview; able to read, speak, and understand English;

\begin{tabular}{|c|c|}
\hline \multicolumn{2}{|c|}{$\begin{array}{l}\text { The Borg scale is used to help us understand the intensity or severity of your } \\
\text { breathlessness. We will ask you to use this scale to rate the intensity } \\
\text { of your breathlessness before, during, and after your exercise. }\end{array}$} \\
\hline \multicolumn{2}{|c|}{ Please review the scale to see the various levels from which you can choose. } \\
\hline \multicolumn{2}{|c|}{ The top of the scale, "0 or nothing at all," means no breathlessness at all. } \\
\hline \multicolumn{2}{|r|}{$\begin{array}{l}\text { The bottom of the scale, "10 or maximal," means the most severe breathlessness that } \\
\text { you have ever experienced or could imagine experiencing. }\end{array}$} \\
\hline \multicolumn{2}{|r|}{$\begin{array}{l}\text { When we ask you to rate the intensity of your breathlessness, please place the tip of } \\
\text { your finger on the number that best describes the intensity that you are experiencing } \\
\text { at that moment. You may also place a finger between } 2 \text { numbers if that better describes } \\
\text { the intensity of your breathlessness. }\end{array}$} \\
\hline \multicolumn{2}{|c|}{ Please let us know if you have any questions before we begin. } \\
\hline 0 & Nothing at all \\
\hline 0.5 & Very, very slight (just noticeable) \\
\hline 1 & Very slight \\
\hline 2 & Slight \\
\hline 3 & Moderate \\
\hline 4 & Somewhat severe \\
\hline 5 & Severe \\
\hline \multicolumn{2}{|l|}{6} \\
\hline 7 & Very severe \\
\hline \multicolumn{2}{|l|}{8} \\
\hline 9 & Very, very severe (almost maximal) \\
\hline 10 & Maximal \\
\hline
\end{tabular}

Figure 3 The standardized version of the modified Borg scale (MBS(S)) tested in Stage 2. 
and able to provide written informed consent. To ensure that participants were able to accurately recall the experience of exercise testing, all participants were to have completed a standardized - incremental or constant workload - exercise program in the form of treadmill or cycle ergometry activities within 24 hours of the interview.

Exclusion criteria were as follows: clinically relevant medical or psychiatric condition(s) that would interfere with completing the study, including but not limited to sensory problems, cognitive impairment, acute mental illness, or inadequately-treated depression or anxiety; COPD exacerbation or unexpected visit to the clinic, emergency room (ER), or hospital, and/or prescription medication to treat an exacerbation within the past four weeks; exercise capacity that is unduly limited by comorbid conditions other than COPD, including but not limited to cardiovascular diseases, neurologic diseases, musculoskeletal diseases, and chronic leg pain/discomfort; diagnosis of asthma; body mass index (BMI) of 35 or above; and respiratory disease other than COPD that contributes to ventilatory limitation during the performance of exercise (ie, pulmonary resection, bronchiectasis, pulmonary hypertension, or interstitial lung disease).

\section{Procedures}

All interviews lasted approximately 60 minutes, and were conducted by trained, experienced interviewers using a semi-structured interview guide. All participants were interviewed within 24 hours of a recent exercise in the clinic. After obtaining informed consent, the interview began with concept elicitation methods. ${ }^{10,11}$ Open-ended questions were used to elicit information from the participants regarding their experience with (and descriptions of) breathlessness during their recent standardized physical exercise. To help anchor patients' experiences of breathlessness, they were initially asked to describe their experience of breathlessness in daily life, followed by their experience of breathlessness during exercise events in the clinic.

The second half of the interview was designed to evaluate the clarity, comprehensiveness, and relevance of the single-item, patient-reported measures of breathlessness using a cognitive interviewing methodology. To collect data to characterize the sample, participants completed a short questionnaire providing basic sociodemographic information and their COPD-related health status on the Saint George's Respiratory Questionnaire for COPD (SGRQ-C) at the end of the interview. ${ }^{35,36}$ Clinical site personnel completed forms documenting the eligibility of participants for the study, along with basic clinical information about the participants. They also completed the modified Medical Research Council (mMRC) Grading System with their rating of the degree of the participants' dyspnea to different levels of activity on the five-point $\mathrm{mMRC}$ scale.

\section{Data analysis}

To explore content validity, transcripts were cleaned and entered into a database for analyses, which were conducted using the ATLAS.ti (version 5.0; Atlas.ti GmbH, Berlin, Germany) qualitative analysis software program. A coding dictionary was developed based on the interview guide and review of the transcripts. This dictionary was used to guide the transcript coding process. The list of codes included a section for the concept elicitation portion of the interview, to capture the terms and phrases that the participants used to describe their breathing, as well as codes for the cognitive interviewing portion of the interview, which captured comments regarding each of the scales. Descriptive statistics to characterize the participant sample were computed using SAS software (version 9.1; SAS Institute, Cary, NC).

\section{Results}

\section{Description of sample}

Demographic and clinical characteristics of the study sample are shown in Table 1. Participants reported comorbid conditions, and $30 \%(\mathrm{n}=4)$ of participants had comorbid cardiovascular disease. In terms of the recently completed exercise, five patients had completed a treadmill exercise, and eight had completed an exercise on the cycle ergometer.

\section{Concept elicitation: participants descriptors of their experience of dyspnea}

Participants described their experience of dyspnea in their daily life using such terms as "shortness of breath", "can't get my breath", "out of breath", and "hard to breathe." "Shortness of breath" was the term most consistently used by participants $(n=5)$ to describe situations in which they had difficulty breathing. When probed about the terms used in the single-item patient-reported outcome scales that evaluate dyspnea intensity (eg, breathlessness, shortness of breath, and discomfort with breathing), most responded that they used the term "shortness of breath" to describe their difficulty breathing day to day, or during normal daily activities. Shortness of breath was described as a feeling of not getting enough air or being unable to get their breath; breathlessness was most commonly defined as being unable to catch their breath. When probed, most participants agreed 
Table I Sociodemographic and clinical characteristics ${ }^{\mathrm{a}}$

\begin{tabular}{|c|c|}
\hline Characteristics & $\begin{array}{l}\text { Total sample } \\
(\mathbf{N}=13)\end{array}$ \\
\hline Age mean (SD) & $56.7(6.0)$ \\
\hline Male (\%) & $7(53.8 \%)$ \\
\hline \multicolumn{2}{|l|}{ Racial background - n (\%) } \\
\hline American Indian or Alaska native & I (7.7\%) \\
\hline White & $12(92.3 \%)$ \\
\hline \multicolumn{2}{|l|}{ Employment status - n (\%) } \\
\hline Employed, part-time & $2(15.4 \%)$ \\
\hline Homemaker & I (7.7\%) \\
\hline Retired & $6(46.2 \%)$ \\
\hline Disabled & $4(30.8 \%)$ \\
\hline \multicolumn{2}{|l|}{ Education - n (\%) } \\
\hline$<$ High school or below & $6(46.2 \%)$ \\
\hline Associate degree, technical, or trade school & $3(23.1 \%)$ \\
\hline College or above & $4(30.7 \%)$ \\
\hline $\mathrm{BMI}$ - mean (SD) & $26.2(4.2)$ \\
\hline \multicolumn{2}{|l|}{ GOLD STATUS, n (\%) } \\
\hline GOLD II & $4(30.8 \%)$ \\
\hline GOLD III & $6(46.2 \%)$ \\
\hline GOLD IV & $3(23.1 \%)$ \\
\hline \multicolumn{2}{|l|}{ mMRC, n (\%) } \\
\hline I & $3(23.1 \%)$ \\
\hline 2 & $7(53.8 \%)$ \\
\hline 3 & $2(15.4 \%)$ \\
\hline 4 & I (7.7\%) \\
\hline \multicolumn{2}{|l|}{ Smoking history, n (\%) } \\
\hline Exsmoker & $13(100.0 \%)$ \\
\hline Total pack-years smoked - mean (SD) & $46.5(25.7)$ \\
\hline Years since diagnosis - mean (SD) & $5.4(3.0)$ \\
\hline \multicolumn{2}{|l|}{ Spirometry ${ }^{b}$} \\
\hline $\mathrm{FEV}_{1}(\mathrm{~L})$ - mean $(\mathrm{SD})$ & $\mathrm{I} .3(0.7)$ \\
\hline $\mathrm{FEV}_{1}(\%$ predicted $)-$ mean (SD) & $38.8(15.1)$ \\
\hline $\mathrm{FEV}_{1} / \mathrm{FVC}(\%)-$ mean $(\mathrm{SD})^{\mathrm{c}}$ & $38.2(13.1)$ \\
\hline Number of COPD exacerbations in past & I.I (I.8) \\
\hline 12 months - mean (SD) & \\
\hline
\end{tabular}

Notes: ${ }^{a}$ As assessed by clinic site personnel; bvalues within 12 months of interview 'data from one participant was missing.

that shortness of breath and breathlessness were similar; three of the 12 participants who discussed this indicated that being breathless was more severe than being short of breath. A few examples of participants' descriptions of these terms are provided in Table 3.

Participants were then asked to describe their breathing during exercise in the clinic/rehab setting. Participants used a variety of descriptors to describe the intensity of dyspnea experienced during their recently-completed clinic-based exercise. Table 4 shows the terms used by the participants to describe the severe end of the dyspnea that they experienced.

A majority of participants $(n=11)$ responded that the magnitude of breathlessness they experienced in daily life was different from that experienced during exercise in
Table 2 Patient report of health status

\begin{tabular}{|c|c|}
\hline \multicolumn{2}{|c|}{ Health status, $\mathbf{n}(\%)$} \\
\hline Excellent & I (7.7\%) \\
\hline Very good & I (7.7\%) \\
\hline Good & $6(46.2 \%)$ \\
\hline Fair & $3(23.1 \%)$ \\
\hline Poor & $2(15.4 \%)$ \\
\hline \multicolumn{2}{|c|}{ Physical exercise outside of the rehab clinic, $n$ (\%) } \\
\hline No & $6(46.2 \%)$ \\
\hline Yes & 7 (53.8\%) \\
\hline \multicolumn{2}{|c|}{ Degree of daily activity limitation because } \\
\hline \multicolumn{2}{|c|}{ of breathlessness, $\mathbf{n}(\%)$} \\
\hline Slightly limited & $5(38.5 \%)$ \\
\hline Moderately limited & $7(53.8 \%)$ \\
\hline Very limited & I (7.7\%) \\
\hline \multicolumn{2}{|c|}{ Scores on the SGRQ-Ca - Mean (SD) } \\
\hline Total & $52.7(17.2)$ \\
\hline Symptom & $56.2(20.1)$ \\
\hline Activity & $69.8(16.8)$ \\
\hline Impact & $41.2(19.6)$ \\
\hline
\end{tabular}

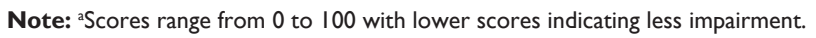

the clinic. While two participants felt their experience of breathlessness was the same, two participants responded they experienced a greater degree of breathlessness during exercise in the clinic than they experienced at home. This was attributed to the fact that, while in daily life, they could modify the speed of their activity; during the exercise in the clinic, they were unable to control the speed or incline. Nine participants felt they experienced less breathlessness during exercise in the clinic than they did performing daily activities or exercising at home. It must be noted that participants were allowed supplemental oxygen during their exercise.

\section{Cognitive interviewing following administration of the three scales}

The VAS-D was only included in the first phase of the debriefing interviews. None of the participants preferred this scale to the NRS-D and MBS. Participants were able to respond to the NRS-D without difficulty. The participants clearly understood the anchor descriptions of "no breathlessness at all" and "breathlessness as bad as it can be," and were able to select a response that corresponded to their level of breathlessness using the response options.

Participants were able to follow instructions and respond to the MBS (Kendrick ${ }^{23}$ version) in Stage 1 and the MBS(S) in Stage 2 without difficulty. They were able to understand what they were supposed to rate; they interpreted it as rating their breathing, and how hard/difficult their breathing was. Participants in the study were familiar with the scale due to its use in their rehab setting, and found it easy to select a response option. Most participants reported using both the 
Table 3 Examples of participants' descriptions when probed about terms used for dyspnea in the single-item patient-reported outcome tools: "shortness of breath", "breathlessness", and "discomfort with breathing"

\begin{tabular}{|c|c|c|c|}
\hline $\begin{array}{l}\text { Participant ID } \\
\text { (GOLD stage) }\end{array}$ & Shortness of breath (SOB) & Breathlessness & Discomfort with breathing \\
\hline III - (GOLD II) & $\begin{array}{l}\text { I just can't catch my breath. I can't get a, } \\
\text { a full lung of air - lungs of air }\end{array}$ & & $\begin{array}{l}\text { Only to the extent of not being able } \\
\text { to - you know, there is no pain, okay? } \\
\text { I mean, there's certainly no pain. But, } \\
\text { it, uh - if, if my - if I'm, you know, so } \\
\text { short of breath, and I'm kind of gasping, } \\
\text { or something, I mean, that's - to me, } \\
\text { is - it's a discomfort, I guess }\end{array}$ \\
\hline II 2 - (GOLD II) & Just out of breath & I guess being out of breath & $\begin{array}{l}\text { Well, to me, it would be if it hurt. } \\
\text { If it hurt, okay, and where would } \\
\text { it hurt? } \\
\text { I don't know. I've never had - I guess in } \\
\text { your lungs, I mean }\end{array}$ \\
\hline I08- (GOLD III) & $\begin{array}{l}\text { Uh, shortness of breath - well, just going } \\
\text { slower and, and knowing that you're near } \\
\text { the verge of breathlessness and whatever } \\
\text { you're doing you stop with breathlessness }\end{array}$ & $\begin{array}{l}\text { Breathlessness, to me, means } \\
\text { unable to do anything }\end{array}$ & $\begin{array}{l}\text { It means, uh, not having my use, uh, } \\
\text { the total breathing that I would } \\
\text { normally have }\end{array}$ \\
\hline II 0 - (GOLD III) & Can't move enough air in and out & $\begin{array}{l}\text { Uh, it would be-to me it means } \\
\text { the same thing as short of breath, } \\
\text { um, like I say, uh, can't move } \\
\text { enough air in and out }\end{array}$ & $\begin{array}{l}\text { Uh, just like a heavy - my chest feels } \\
\text { like it's real heavy, like somebody's } \\
\text { sitting on me }\end{array}$ \\
\hline II3 - (GOLD-IV) & $\begin{array}{l}\text { Shortness of breath just means - it's } \\
\text { I have to breathe a little faster }\end{array}$ & $\begin{array}{l}\text { Breathlessness means that it feels } \\
\text { like l'm not getting any air }\end{array}$ & $\begin{array}{l}\text { Where I have a lot of pain when I take } \\
\text { a deep breath }\end{array}$ \\
\hline
\end{tabular}

numbers and the descriptions to help them select their answer. Participants were able to distinguish between the descriptors to decide which response option to endorse; evidence of participant understanding of the minimum, mid-level, and maximal response options was seen on cognitive interviewing of both versions of the MBS tested in this study. During cognitive interviews, the descriptors used by the participants to describe their interpretation of the lower (0 and 0.5), mid-level (3-5), and upper (6-8) ends of the scale matched the descriptions used by the participants in the open-ended concept elicitation stage. Participants did not have a problem with 6 and 8 not having descriptors; moreover, no participant could easily define or provide descriptions for these options.

All participants understood the term "maximal." Ten participants linked it to a state of emergency, which would require medical intervention. None of the participants

Table 4 Terms used to describe severe breathlessness during exercise

\begin{tabular}{|c|c|c|c|c|c|c|c|c|c|c|c|c|c|}
\hline \multirow[t]{3}{*}{ Symptom } & \multicolumn{13}{|c|}{ Participant ID } \\
\hline & \multicolumn{4}{|c|}{ GOLD stage 2} & \multicolumn{6}{|c|}{ GOLD stage 3} & \multicolumn{3}{|c|}{ GOLD stage 4} \\
\hline & 102 & 103 & III & 112 & 101 & 106 & 107 & 108 & 109 & 110 & 104 & 105 & 113 \\
\hline Heavy & & $x$ & & & $x$ & $x$ & & & & & & & \\
\hline Fast & & & & $x$ & $x$ & & & & & $x$ & & & \\
\hline Exerting & $x$ & $x$ & & & & & & & & & & & \\
\hline Straining & $x$ & & & & & & & & & & & & \\
\hline Gasping & $x$ & & & & & & $x$ & $x$ & & & & & \\
\hline Heaving & $x$ & & & & & & & & & & & & \\
\hline Hard & & $x$ & & $x$ & & & $x$ & $x$ & & $x$ & & & \\
\hline Difficult & & & $x$ & & & $x$ & $x$ & & $x$ & & $x$ & & $x$ \\
\hline Laboured & & & & & & & & & & $x$ & $x$ & & \\
\hline Passed out & & & & & & & & & & & $x$ & & \\
\hline Draining & & & & & & & & & & & & $x$ & \\
\hline Terrible & & & & & & & $x$ & & & & & $x$ & \\
\hline Rough & & & & & & & & & & & & $x$ & \\
\hline Uncomfortable & & & & & & & & & $x$ & & & & \\
\hline
\end{tabular}


mentioned experiencing maximal breathlessness during a standardized exercise in the clinic, with the reported maximum ranging between 4 and 6 .

\section{Participant preference}

While participants understood all three scales, the VAS-D was not preferred by participants (and was therefore not tested further in Stage 2); participants felt it was more confusing and subjective than the NRS-D. When discussing their preferences, six of the 11 participants spontaneously mentioned that the inclusion of descriptions next to the number in the MBS and $\operatorname{MBS}(\mathrm{S})$ was helpful to them. However, three participants cited the lack of descriptors on the NRS-D as the driving factor behind their preference for that scale.

\section{Discussion and conclusion}

Understanding patients' experiences of dyspnea during a standardized physical exercise is an important consideration for the management of the COPD patient in both the clinical and rehabilitation settings. It is also an endpoint that has been included in clinical trials evaluating the benefits of treatments for COPD. While there have been efforts to standardize the method for evaluative tools for collecting data about this concept using the MBS or the VAS-D, there is a wide variation in the formats, response options, and content; there is also limited evidence about the performance characteristics of these tools. The MBS has been used to evaluate patients' experiences of dyspnea: "effort to breathe" and "degree of respiratory discomfort". ${ }^{25}$ Investigators have asked subjects to rate "severity of breathlessness", "need to breathe", and "effort of breathing." In a recent review of outcome measures in COPD, Glaab and colleagues ${ }^{37}$ suggested the need for more research to optimize and validate the items on the MBS, including direct patient involvement in instrument generation, to enhance their content validity for use in clinical trials. Our study was conducted to obtain information about patients' experiences of dyspnea, and to further standardize these assessments. This will help to ensure that the collection of data accurately reflects patients' experiences, and can be compared across various studies.

The study sample was recruited to reflect the sociodemographic and clinical characteristics of patients usually included in clinical trials. Most (69\%) of these patients were classified as GOLD Stage III or above by the clinician, and three $(23 \%)$ were assigned a grade of 3 ("stops for breath after walking about 100 yards or a few minutes on the level") or more on the mMRC scale. While all participants selfreported some limitations in their daily activities because of breathlessness, only two of the participants rated their overall health status as "poor." Mean scores on the activity domain of the SGRQ-C also suggested impairment in that domain. While we were not able to collect data during the standardized exercise, and recognizing the challenges of conducting interviews immediately following an exercise event, all participants were interviewed within 24 hours of a recent standardized exercise in the clinic.

The following limitations must be mentioned. The sample size was relatively small, and therefore, diversity in the sample was limited. Also, all participants were recruited from a single site in the US where they had been previously evaluated using a version of the MBS. However, the MBS is mentioned as a tool to evaluate dyspnea during exercise in documents by the American Thoracic Society ${ }^{2,21}$ which provide guidance on the conduct of exercise testing; therefore, it is widely used in clinics across the country. Hence, it would be difficult to enroll patients from such programs who had not been exposed to the scale before. It must also be noted that participants did not actually respond to the three scales during their exercise test, but were interviewed within 24 hours of a recent exercise event in the clinic. As suggested by Laveneziana and colleagues, ${ }^{38}$ the level of dyspnea does vary during exercise. The concept elicitation interviews revealed that COPD patients used various terms to describe their experiences of dyspnea associated with exercise. Participants' descriptions of the intensity of severe dyspnea experienced during exercise were similar to those cited by von Leupoldt and colleagues, ${ }^{39}$ who also found that the COPD patients selected descriptors linked with heavy/ fast breathing, including "gasping", to describe the intensity of their experience at the severe end of dyspnea following an exercise event. In this study, the terms "heavy", "hard", "fast", and "gasping" were used by those in GOLD Stages II and III. Though participants did not spontaneously mention the word "breathless", they were able to respond to the instructions that required them to indicate the level of breathlessness. They were also able to discriminate among the various levels/descriptions of intensity as marked on the respective scales. While patient perception of dyspnea may be affected by several factors, it was beyond the scope of this study to examine those in detail.

Participants understood the instructions and format of the three scales - the NRS-D, VAS-D, and MBS (both the Kendrick $^{23}$ version and the MBS[S]) - interpreting the task correctly within the context of exercise. Participants also were able to respond appropriately to all three scales. However, none of the participants preferred the VAS-D. 
It was recognized that participants would not be able to mark the VAS while performing the standardized exercise, unless a method such as a computerized version ${ }^{40}$ could be used to allow participants to mark their response without having to move their hand away from the exercise equipment. Gift and Narsavage ${ }^{33}$ suggested that the NRS-D may be an easier scale to use to assess dyspnea; six participants in this study even preferred the scale over the MBS/MBS(S).

The results from testing the MBS (Kendrick ${ }^{23}$ version) in Stage 1 were used to develop a standardized version of the scale. The MBS(S) was tested with seven patients, and the results of this study support the content validity of the $\operatorname{MBS}(\mathrm{S})$. Participants were able to understand the standardized instructions developed for this study. The scale required participants to select a response to describe the intensity of "breathlessness" experienced before, during, and after the exercise.

We examined a version of the MBS with responses on the $0-10$ scale, which is used more often in COPD studies. We used the version where the maximal intensity would be scored as 10, rather than beyond 10 as in the original CR10 Scale ${ }^{\circledR}$. The finding that the participants in this study did not select a score above 8 on the MBS and MBS(S), together with the participants' descriptions of "maximal", suggests that there is no requirement for the scale to have a response option beyond 10 . The ATS/CCP statement on CPET had also suggested that patients stopped exercising at ratings of 5 to 8 , further supporting the rationale for not requiring an option to score the intensity of dyspnea beyond 10 for a scale to evaluate dyspnea in relation to exercise testing. However, it must be noted that we did not test a version where subjects could select a score above 10 , as in the CR10 Scale.

In conclusion, this study provides initial evidence to support the content validity of the $\mathrm{MBS}(\mathrm{S})$ for use to collect data about dyspnea (breathlessness) associated with exercise in patients with COPD. We recommend using the instructions that were developed for this study and which were well understood by patients. The replication of the process in a more diverse group could further affirm content validity of the $\operatorname{MBS}(\mathrm{S})$ across a wider variety of patients.

\section{Acknowledgments}

The authors would like to acknowledge the following individuals: Dr Richard ZuWallack, St Francis Hospital Medical Center, Hartford, CT, USA, for his review of initial results of the study and guidance on the protocol and versions of scales to be tested; and Brooke Currie, Erin O'Rourke,
Robin Pokrzywinski, and Ren Yu from United BioSource Corporation for their assistance with the patient interviews and data analyses. The authors would also like to thank the clinical site staff for their assistance with patient recruitment. Finally, the authors would like to thank Alan Hamilton from Boehringer Ingelheim for providing background information on early versions of the Borg Scale and its application in clinical trials of exercise testing.

\section{Disclosure}

This study was funded by Boehringer Ingelheim International $\mathrm{GmbH}$. Brigitta U Monz and Karin Becker are employees of Boehringer Ingelheim International GmbH. Asha Hareendran, Nancy Kline Leidy, Randall Winnette, and Donald A Mahler served as paid consultants to Boehringer Ingelheim International $\mathrm{GmbH}$ during the conduct of this study and the development of this manuscript. The authors report no other conflicts of interest in this work.

\section{References}

1. Rennard S, Decramer M, Calverley PM, et al. Impact of COPD in North America and Europe in 2000: subjects' perspective of Confronting COPD International Survey. Eur Respir J. 2002;20(4):799-805.

2. American Thoracic Society/American College of Chest Physicians. ATS/ACCP statement on cardiopulmonary exercise testing. Am J Respir Crit Care Med. 2003;167(2):211-277.

3. Mahler DA, Horowitz MB. Clinical evaluation of exertional dyspnea. Clin Chest Med. 1994;15(2):259-269.

4. Killian KJ, Leblanc P, Martin DH, Summers E, Jones NL, Campbell EJ. Exercise capacity and ventilatory, circulatory, and symptom limitation in patients with chronic airflow limitation. Am Rev Respir Dis. 1992;146(4):935-940.

5. Hamilton AL, Killian KJ, Summers E, Jones NL. Muscle strength, symptom intensity, and exercise capacity in patients with cardiorespiratory disorders. Am J Respir Crit Care Med. 1995;152(6 Pt 1): 2021-2031.

6. US Department of Health and Human Services, Food and Drug Administration, Center for Drug Evaluation and Research (CDER). Guidance for Industry: Chronic Obstructive Pulmonary Disease: Developing Drugs for Treatment. 2007. Available from: http://www. fda.gov/downloads/Drugs/GuidanceComplianceRegulatoryInformation/ Guidances/ucm071575.pdf. Accessed March 5, 2012.

7. American Thoracic Society. Dyspnea: mechanisms, assessment, and management: a consensus statement. Am J Respir Crit Care Med. 1999;159(1): 321-340.

8. Aguilaniu B. Impact of bronchodilator therapy on exercise tolerance in COPD. Int J Chron Obstruct Pulmon Dis. 2010;5:57-71.

9. US Food and Drug Administration. Guidance for industry on patientreported outcome measures: use in medical product development to support labeling claims. Federal Register. 2009;74(235):65132-65133.

10. Patrick DL, Burke LB, Powers JH, et al. Patient-reported outcomes to support medical product labeling claims: FDA perspective. Value Health. 2007;10 Suppl 2:S125-S137.

11. Rothman M, Burke L, Erickson P, Leidy NK, Patrick DL, Petrie CD. Use of existing patient-reported outcome (PRO) instruments and their modification: the ISPOR Good Research Practices for Evaluating and Documenting Content Validity for the Use of Existing Instruments and Their Modification PRO Task Force Report. Value Health. 2009;12(8):1075-1083. 
12. Borg G. A category scale with ratio properties for intermodal and interindividual comparisons. In: Geissler HG, Petzol P, editors. Psychophysical Judgement and the Process of Perception. Proceedings of the 22nd International Congress of Psychology. Amsterdam, The Netherlands: North Holland Publishing Co; 1980:25-34.

13. O'Donnell DE, Fluge T, Gerken F, et al. Effects of tiotropium on lung hyperinflation, dyspnoea and exercise tolerance in COPD. Eur Respir J. 2004;23(6):832-840.

14. O'Donnell DE, Voduc N, Fitzpatrick M, Webb KA. Effect of salmeterol on the ventilatory response to exercise in chronic obstructive pulmonary disease. Eur Respir J. 2004;24(1):86-94.

15. Teramoto S, Fukuchi Y, Orimo H. Effects of inhaled anticholinergic drug on dyspnea and gas exchange during exercise in patients with chronic obstructive pulmonary disease. Chest. 1993;103(6):1774-1782.

16. Ayers ML, Mejia R, Ward J, Lentine T, Mahler DA. Effectiveness of salmeterol versus ipratropium bromide on exertional dyspnoea in COPD. Eur Respir J. 2001;17(6):1132-1137.

17. Maltais F, Celli B, Casaburi R, et al. Aclidinium bromide improves exercise endurance and lung hyperinflation in patients with moderate to severe COPD. Respir Med. 2010;105(4):580-587.

18. Borg GA. Psychophysical bases of perceived exertion. Med Sci Sports Exerc. 1982;14(5):377-381.

19. Borg G. Perceived exertion as an indicator of somatic stress. Scand J Rehabil Med. 1970;2(2):92-98.

20. Borg G, Borg E. The Borg CR Scales ${ }^{\circledR}$ Folder. Hasselby, Sweden: Borg Perception; 2010.

21. ATS Committee on Proficiency Standards for Clinical Pulmonary Function Laboratories. ATS statement: guidelines for the six-minute walk test. Am J Respir Crit Care Med. 2002;166(1):111-117.

22. Burdon JG, Juniper EF, Killian KJ, Hargreave FE, Campbell EJ. The perception of breathlessness in asthma. Am Rev Respir Dis. 1982;126(5):825-828.

23. Kendrick KR, Baxi SC, Smith RM. Usefulness of the modified 0-10 Borg scale in assessing the degree of dyspnea in patients with COPD and asthma. J Emerg Nurs. 2000;26(3):216-222.

24. Leblanc P, Bowie DM, Summers E, Jones NL, Killian KJ. Breathlessness and exercise in patients with cardiorespiratory disease. Am Rev Respir Dis. 1986;133(1):21-25.

25. Mador MJ, Rodis A, Magalang UJ. Reproducibility of Borg scale measurements of dyspnea during exercise in patients with COPD. Chest. 1995;107(6):1590-1597.

26. Wilson RC, Jones PW. A comparison of the visual analogue scale and modified Borg scale for the measurement of dyspnoea during exercise. Clin Sci (Lond). 1989;76(3):277-282.
27. Mahler DA, Mejia-Alfaro R, Ward J, Baird JC. Continuous measurement of breathlessness during exercise: validity, reliability, and responsiveness. J Appl Physiol. 2001;90(6):2188-2196.

28. Coppoolse R, Schols AM, Baarends EM, et al. Interval versus continuous training in patients with severe COPD: a randomized clinical trial. Eur Respir J. 1999;14(2):258-263.

29. Sassi-Dambron DE, Eakin EG, Ries AL, Kaplan RM. Treatment of dyspnea in COPD. A controlled clinical trial of dyspnea management strategies. Chest. 1995;107(3):724-729.

30. Cazzola M, MacNee W, Martinez FJ, et al. Outcomes for COPD pharmacological trials: from lung function to biomarkers. Eur Respir J. 2008;31(2):416-469.

31. Janson-Bjerklie S, Carrieri VK, Hudes M. The sensations of pulmonary dyspnea. Nurs Res. 1986;35(3):154-159.

32. Gift AG. Validation of a vertical visual analogue scale as a measure of clinical dyspnea. Rehabil Nurs. 1989;14(6):323-325.

33. Gift AG, Narsavage G. Validity of the numeric rating scale as a measure of dyspnea. Am J Crit Care. 1998;7(3):200-204.

34. Maltais F, Hamilton A, Marciniuk D, et al. Improvements in symptomlimited exercise performance over $8 \mathrm{~h}$ with once-daily tiotropium in patients with COPD. Chest. 2005;128(3):1168-1178.

35. Jones PW, Quirk FH, Baveystock CM. The St George's Respiratory Questionnaire. Respir Med. 1991;85 Suppl B:25-31, discussion 33-27.

36. Meguro M, Barley EA, Spencer S, Jones PW. Development and validation of an improved COPD-specific version of the St George's Respiratory Questionnaire. Chest. 2006;132(2):456-463.

37. Glaab T, Vogelmeier C, Buhl R. Outcome measures in chronic obstructive pulmonary disease (COPD): strengths and limitations. Respir Res. 2010;11:79.

38. Laveneziana P, Webb KA, Ora J, Wadell K, O’Donnell DE. Evolution of dyspnea during exercise in chronic obstructive pulmonary disease: impact of critical volume constraints. Am J Respir Crit Care Med. 2011;184(12):1367-1373.

39. von Leupoldt A, Balewski S, Petersen S, et al. Verbal descriptors of dyspnea in patients with COPD at different intensity levels of dyspnea. Chest. 2007;132(1):141-147.

40. Mahler DA. Mechanisms and measurement of dyspnea in chronic obstructive pulmonary disease. Proc Am Thorac Soc. 2006;3(3): 234-238.
International Journal of COPD

\section{Publish your work in this journal}

The International Journal of COPD is an international, peer-reviewed journal of therapeutics and pharmacology focusing on concise rapid reporting of clinical studies and reviews in COPD. Special focus is given to the pathophysiological processes underlying the disease, intervention programs, patient focused education, and self management protocols.

\section{Dovepress}

This journal is indexed on PubMed Central, MedLine and CAS. The manuscript management system is completely online and includes a very quick and fair peer-review system, which is all easy to use. Visit http://www.dovepress.com/testimonials.php to read real quotes from published authors. 